\title{
REMOTE-LECTURE COOPERATIVE SOFTWARE SYSTEM FOR THE COMPUTER-INTEGRATED CLASSROOM
}

\author{
Felipe Baytelman P. $^{1}$, Nelson Baloian ${ }^{2}$, Mitsuji Matsumoto ${ }^{1}$ \\ Graduate School of Global Information and Telecommunication Studies ${ }^{1}$, \\ Waseda University, Tokyo, Japan \\ Departamento de Ciencias de la Computación ${ }^{2}$, \\ Universidad de Chile, Santiago, Chile
}

\begin{abstract}
Current state of remote lecture software has several problems: it promotes a teacher-centered teaching/learning style, it does not provide the lecturer with new tools compatible with today's technology, it limits teacher's freedom during classes, the audience cannot follow on-the-fly-created lectures in their personal computers, and remote students cannot participate or interact with the main class from their local eboard or computer. We propose to develop a new software system, non-invasive, based on free drawing, synchronous interaction, and remotely controlled, which will enable a more rich interaction between teacher and students. This will allow the teacher to express him/her more freely, and distant students to participate more actively in lectures.
\end{abstract}

\section{INTRODUCTION}

Nowadays, the explosive Internet and broadband development has opened a whole new dimension to education: distance synchronous teaching/learning allows student far away from their teachers to follow the classes by viewing them on real-time video conferences, as well as following pre-prepared presentations for each lecture, directly by accessing them through Internet, or replaying teacher's screen in local projector [1].

This helps geographically distributed academic organizations to still work together closely. The recent moving of part of the GITS facilities from NishiWaseda Campus to Honjo, ninety kilometers away from Tokyo, is an excellent example of the need of distance-learning remote lecturing sessions. Every day, students participate in remote lectures by videoconference, allowing them to take part of a class they could not attend physically. Teacher's presentation is projected on both classrooms, so students can follow the lecture as the teacher speaks. Although attending to presentations remotely is substantially inferior to faceto-face participating, it is better than not having the opportunity of following the lecture at all. Being part of the local audience and watching the class through a screen is definitely different: The professor is not

0-7803-8560-8/04/\$20.00@2004IEEE able to call remote students to do some exercises in the board. Moreover, sometimes the distant audience does not have any real whiteboard to look to. They only see a projected replay of original e-board's screen on the wall. So, It is obvious that results will be different.

We propose the design and development of a new educational software system, which will support the performance of remote lectures by allowing teachers to develop high-quality learning contents on-the-fly. This will be based on non-invasive tools recognizing teacher's gestures instead of using menues or floating palettes which may distract the focus of attention of the audience on the important parts of the learning material being presented [2]. This software will also have the ability of being manipulated by remote interaction. Figure 1 shows an example of this collaborative software.

Local Classroom Remote Classroom

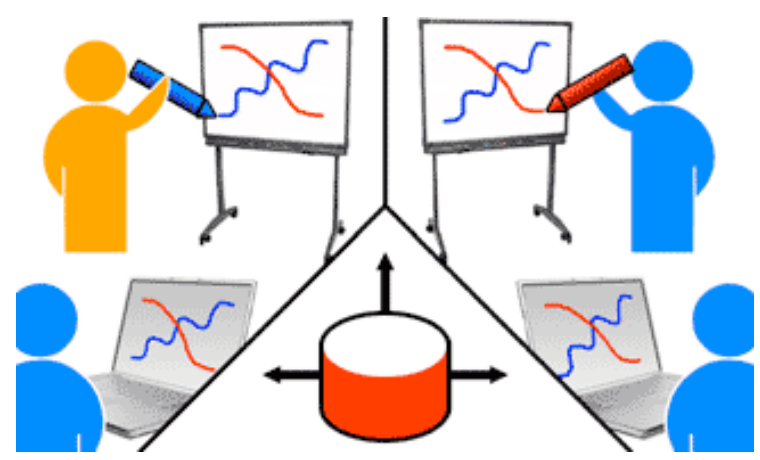

Fig. 1. Remote access collaborative classroom

\section{MAIN PROBLEMS}

Current systems do not provide teachers and students with tools which allow them to achieve in remote lectures the same results as in face-to-face lectures [3]. Certainly, existing technology is not being fully exploited.

\subsection{Currently used software was not designed for education}

We realize that mostly all used software, like Adobe Acrobat, Microsoft PowerPoint, Microsoft Windows, 
or Smart Notebook, was not designed specifically for educational purposes [2]. In fact, currently there is no appropriate educational-lecture tool able to mix both, the ability of writing and drawing, and the power of generating high quality documents or graphics on-thefly easily, without interrupting the class. [3]

\subsection{Students cannot access remote white-board}

Some campus, like Honjo and Nishi-Waseda, are provided with a complete set of tools to support remote lectures, from video-conferencing systems to electronic boards. Although remote classroom's e-board is not being used at all, and students cannot participate apart from asking questions to the professor through the camera.

\subsection{Teacher-centered environment}

Some teachers maintain certain skepticism to the integration of the technology in their classrooms. [4] They think the computer will interfere the natural course of their class, and they are right: Current tools create a teacher-centered environment, i.e., if the teacher explains any idea by drawing over the slides, or switches from one application to another, students cannot equally participate, and if they want to follow what the teacher is explaining, they must individually reproduce the same action in their personal computers, affecting their concentration on professors' speech [2].

\subsection{Technology limits teacher freedom}

The main goal of technology in the classroom is to improve local and remote classes: Help teachers get the most from available devices like e-boards, without interrupting the normal development of classes. But current state of computer-given lectures is restricted to a few options: playing a lineal slide show, using a computer to show pre-prepared documents, or hand writing over the screen. The first two do not give the freedom to develop new contents during a class [3] and the third one does not use all the potentials of the e-board.

\section{ANALYSIS AND PROPOSAL APPROACH}

New technologies are meant to improve and make our activities easier. For example, introduction of webbased learning has given students many advantages, like studying whenever they want to or reducing time and money spent on traveling [5], but we have to keep in mind that face-to-face learning is not replaceable and, therefore, we are not looking to replace the teacher-student relationship. [3]

\subsection{New educational software}

We do want to improve education, but at the same time, we do not want to introduce disturbing elements. We have to recognize in the available technological resources the advantages we want to exploit, and the disadvantages we need to avoid. Then we will focus on developing a new educational software, in order to solve the problems already mentioned.

\subsection{Non-invasive system}

Traditionally, teachers have used a normal white board in order to explain their ideas. Professors represent these concepts exclusively with pens and gestures, not floating-tools or anything more advanced than writing, erasing and using their hands. So, introducing new elements to the equation may alter original results. Thus, the less we interrupt professors' teaching, the less we will distort its primary target: to teach. In this way, we will reduce teachers' skepticism towards technology in their classes. Then, our first objective is to develop a non-invasive system.

\subsection{E-board interface based on gestures}

Previous work has shown positive results based on software developed specifically for e-boards. Preceding research and design in electronic-board-supported classes has created and tested Java-FreeStyler, a software aimed to improve Java lectures with e-boards, which avoids context changes during classes, thus increasing students attention [2]. They proved that using this program specifically designed to teach Java using interactive boards, better results may be achieved than using standard developed software. They focused on solving the context change issue, and they succeeded: Precise objectives lead to precise results. Therefore, our second objective is to focus our efforts towards a clear large screen interface design [6, 7] aimed to help teaching in precise ways. We will concentrate in designing a special interface that allows traditional teaching to be translated in high-quality vector-based graphics in real time, based on common teachers' gestures over an electronic board. Figure 2 shows an example of drawings before and after recognition.

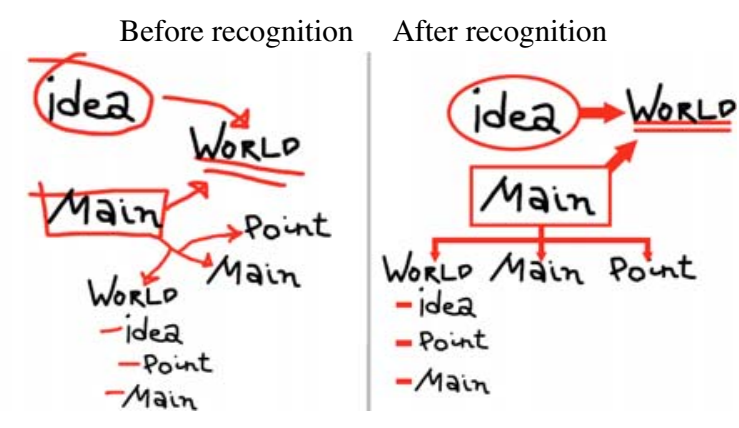

Fig. 2. Gestures recognition example

\subsection{Remote collaborative system}

Waseda GITS campus has recently moved to Honjo, outside Tokyo. Students need to travel for one hour and a half from one place to the other, so physically attending lectures given in the other campus is quite time consuming. This is why remote lectures are of great 
importance. For this, they have set a screen-sharing scheme, parallel to a videoconference system, both based on broadband connectivity. This setup allows both classrooms to share almost the same experience, but one clearly has the privilege of being the main classroom, where the teacher is. So remote students cannot physically feel the teacher's presence, as well as the teacher cannot feel theirs. This sensation gets increased when students in one classroom can see the teacher drawing in the board, and the others see the result projected in they local screen. In fact, teachers could ask a local student to do exercises in the board, but he cannot call a remote student. This makes the situation even more unjust. In order to turn this scenario fairer, both groups should have same opportunities. Our third objective is to allow remote attendees to interact with a local e-board as if they were in the same classroom than the rest.

\section{CONCLUSION}

Current remote-lecture software should be improved in order to satisfy the needs of distance teaching/learning in Computer-Integrated Classrooms.

We propose to develop a new Java-based, noninvasive collaborative software, based on gestures, developed specifically for the educational scope, which will enable a more rich interaction between teacher and students.

\section{SUMMARY AND FUTURE WORK}

We now have summarized our solution proposal in order to solve current problems in remote teaching/learning systems: To build a new software system, based on Java technology, developed specifically for remote lectures between multiple ComputerIntegrated Classrooms. Figure 3 shows the overall workflow of the system.

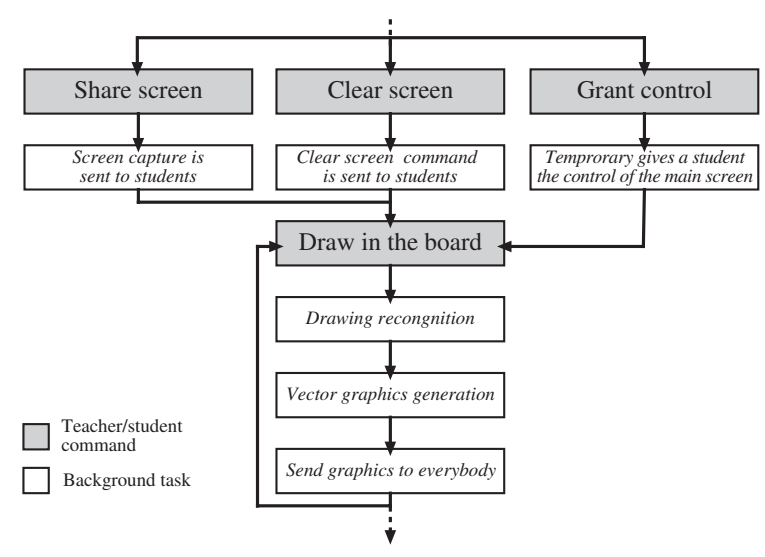

Fig. 3. Overall system workflow
261

With this software students would be able to share teacher's screen in their own computers, in local or remote classrooms, without depending on what platform they use, because it will be based on Java technology. Also, this system would allow teachers to grant screen control to any student, so that everyone, indepenently on his location, could participate in the class equally.

Initially, software will capture professor's screen and then share it with the rest of the audience. Later, when the professor begins to make explanations over the slides, after each drawing is made, recognition system will translate the writing in graphical objects based on vector graphics, using few bytes, instead of capturing the whole screen bitmap. Then, these elements will be multicasted to all student who follows the class.

\section{REFERENCES}

[1] N. Baloian, H. U. Hoppe and U. Kling, ”Structural Authoring and Cooperative use of Instructional Multimedia Material for the Computer Integrated Classroom", Proc. ED-Media, pp. 81-86, Graz, Austria, 1995.

[2] L. Llanza, "Human-Computer Interfaces for Electronic Board Supporting face-to-face Knowledge Exchange", Graduate School of Global Information and Telecommunication Studies, Waseda University, Tokyo, Japan, 2004.

[3] N. Baloian et al., "Document Management in a Computer-Integrated Classroom", Proc. CRIWG, 8th International Workshop on Groupware, pp. 35-46, La Serena, Chile, 2002.

[4] C. Holden, "Computers Make Slow Progress in Class", Computer Science, 244, pp. 906-909, May, 1989.

[5] V. Uskov and A. Uskov, "Blending Streaming Multimedia and Communication Technology in Advanced Web-based Education", Advanced Technology for Learning, Vol. 1, No. 1, pp. 54-65, 2004.

[6] D. Norman, "The design of everyday things", Currency-Doubleday, New York, 1988.

[7] D. Norman, "In an Interview with Don Norman", The Art of Human-Computer Interface Design, AddisonWesley, pp. 5-10, 1990.

[8] F. Guimbretiere, M. Stone and T. Winograd, "Stick it on the Wall: A Metaphor for Interaction with Large Displays", Proc. CHI'01 Workshop on Tools, Conceptual Frameworks, and Empirical Studies for Early Stages of Design, Seattle, Washington, USA, April, 2001.

[9] T. D. Moran, W. van Melle and P. Chiu, "Spatial Interpretation of Domain Objects Integrated into a Freedom Form Electronic Whiteboard", Proc. ACM Symposium of User Interface Software and Technology, pp. 175184, San Francisco, CA, USA, 1998. 